Journal of Patient-Centered

$1-17-2022$

\title{
A Physical Therapy Mobility Checkup for Older Adults: Feasibility and Participant Preferences From a Discrete Choice Experiment
}

Dalerie Lieberz

Hannah Borgeson

Steven Dobson

Lindsey Ewings

Karen Johnson

Kori Klaysmat

Abby Schultz

Rachel Tasson

Alexandra L. Borstad

Follow this and additional works at: https://aah.org/jpcrr

Part of the Family Medicine Commons, Geriatric Nursing Commons, Geriatrics Commons, Health Services Research Commons, Other Analytical, Diagnostic and Therapeutic Techniques and Equipment Commons, Physical Therapy Commons, and the Physiotherapy Commons

\section{Recommended Citation}

Lieberz D, Borgeson H, Dobson S, Ewings L, Johnson K, Klaysmat K, Schultz A, Tasson R, Borstad AL. A physical therapy Mobility Checkup for older adults: feasibility and participant preferences from a discrete choice experiment. J Patient Cent Res Rev. 2022;9:24-34. doi: 10.17294/2330-0698.1874

Published quarterly by Midwest-based health system Advocate Aurora Health and indexed in PubMed Central, the Journal of Patient-Centered Research and Reviews (JPCRR) is an open access, peer-reviewed medical journal focused on disseminating scholarly works devoted to improving patient-centered care practices, health outcomes, and the patient experience. 


\title{
A Physical Therapy Mobility Checkup for Older Adults: Feasibility and Participant Preferences From a Discrete Choice Experiment
}

\author{
Dalerie Lieberz, PhD, DPT, ${ }^{1}$ Hannah Borgeson, DPT, ${ }^{2}$ Steven Dobson, DPT, ${ }^{3}$ Lindsey Ewings, DPT, ${ }^{1}$ \\ Karen Johnson, DPT, ${ }^{4}$ Kori Klaysmat, DPT, ${ }^{1}$ Abby Schultz, DPT, ${ }^{1}$ Rachel Tasson, DPT, ${ }^{1}$ Alexandra L. \\ Borstad, PhD, $\mathrm{PT}^{1}$ \\ ${ }^{1}$ Department of Physical Therapy, The College of St. Scholastica, Duluth, MN; ${ }^{2}$ St. Luke's Medical Clinic, Mountain \\ Iron, MN; ${ }^{3}$ Therapeutic Associates Physical Therapy, Eugene, OR; ${ }^{4}$ Big Stone Therapies, Inc., Marshall, MN
}
Purpose $\quad$ Physical performance measures, like walking speed, identify and predict preclinical mobility disability but are rarely used in routine medical care. A preventive model of care called Mobility Checkup is being designed to reduce mobility disability in older adults. This study had two purposes: 1) determine feasibility and outcomes of the Mobility Checkup, and 2) identify preferences of older adults regarding this model of care using a discrete choice experiment.

Methods Adults over 55 years of age were recruited from the community. In the study's first phase, participants completed a Mobility Checkup, with feasibility evaluated using 6 criteria. In the second phase, a new sample of older adults ( $>55$ years old) were educated about the Mobility Checkup and then completed a discrete choice experiment to determine their preferences regarding 4 attributes of this care model: cost, visit duration, desired education topic, and style of educational graphic.

Results Each study phase was completed by 31 participants. Of the 6 feasibility criteria, 5 were met. Visit duration exceeded the 60 -minute criteria for 13 of the 31 participants. Still, $91 \%$ of participants were very satisfied with the Mobility Checkup. Ability to transition positions identified preclinical mobility disability most frequently. A 30-minute visit with no out-of-pocket cost was deemed preferred.

Conclusions Older adults value knowing what physical performance measurements predict about their general health. Transitions should be evaluated as part of a Mobility Checkup for older adults. Clearly conveyed cost of health care service is important to older adult consumers. ( $\mathrm{J}$ Patient Cent Res Rev. 2022;9:24-34.)

Keywords mobility disability; older adults; preclinical; preventive care; healthy aging; routine care; patient preferences

$\mathrm{D}$ o you know your walking speed? Do you know what it indicates about your health? Most people do not. Unlike blood pressure or body mass index, physical performance measures, such as walking speed, are rarely used as health indicators in routine medical care. ${ }^{1}$ This is a missed opportunity, particularly for older adults, who may experience subtle, gradual decline in physical performance that leads to mobility disability. ${ }^{2,3}$ Development of a "Mobility Checkup," a preventive model of physical therapy care that prioritizes educating

Corresponding author: Dalerie Lieberz,

Department of Physical Therapy, College of St. Scholastica, 940 Woodland Ave., Duluth, MN 55812 (dlieberz@css.edu) older adults on the value of physical performance as an indicator of health, could result in a cost-effective tool to prevent physical decline with aging.

Healthy aging has been defined as "the process of developing and maintaining the functional ability that enables well-being in older age" and includes mobility, ie, moving with ease in your home, community, and beyond. ${ }^{4}$ Early, subtle changes in mobility are referred to as preclinical mobility disability. Preclinical mobility disability is known to predict mobility disability., Mobility disability has been defined as the inability to walk 400 meters and to climb a flight of stairs without assistance. ${ }^{7}$ Chronic conditions associated with an increased prevalence of mobility disability in older adults include osteoporosis, arthritis, sarcopenia, cardiac abnormalities, high blood pressure, ${ }^{8-10}$ acquired 
neurologic conditions, and pain. ${ }^{11}$ Mobility disability is associated with an increased risk for falls, reduced access to medical services, poor mental well-being, worse health outcomes, ${ }^{12}$ and poorer quality of life. ${ }^{13}$ Mobility disability is also associated with a reduced likelihood of aging in place, ${ }^{14}$ which is the preference of most older adults in the United States. ${ }^{15}$

The position of the American Physical Therapy Association is that all people should have an annual physical therapy visit to "optimize movement and promote health, wellness, and fitness; and slow progression of impairments of body functions and structures, activity limitations, and participation restrictions." ${ }^{16}$ Physical therapy leaders agree this specialty should further position itself as direct access providers and develop prevention programs that are patient-centered. ${ }^{17-20}$ While these important recommendations support preventive care for maintaining mobility, a model of care specific to prevention of mobility disability in older adults is not common practice. ${ }^{19,21}$ Evidence suggests screening can predict mobility disability in older adults ${ }^{22-24}$ and that activity-based interventions prevent it. ${ }^{25-30}$

The Mobility Checkup developed and studied herein has two parts: measurement and education. It was designed to identify preclinical or mobility disability in older adults and provide education in a way that guides them to choose activity to optimize mobility and health. Determining the feasibility of this specific Mobility Checkup and the preferences of older adults for this model of care are critical prerequisites to implementation and evaluating its effectiveness in future studies.

Discrete choice experiments (DCEs) are a survey-based approach to determine which attributes of a good or service consumers value. DCEs have been used in health economics research since 1990 to determine health care processes valued by patients. ${ }^{31}$ This method can elicit the preferences of consumers, ${ }^{31-33}$ including the expected uptake of novel health care products. ${ }^{33}$ The rationale for using a DCE in our study was its quantitative nature and ability to elicit preferences implicitly, which is thought to reduce bias compared to traditional survey approaches. ${ }^{33}$ DCEs are known to be valid ${ }^{17}$ and reliable over time for both input (consistency of responses to questions) and output (consistency of preference results). ${ }^{34,35}$ Finally, DCEs enable examining multiple options (levels of attributes) within plausible health care scenarios. The specific DCE attributes studied for this Mobility Checkup were: preferred out-of-pocket cost, visit duration, desired education on specific mobility constructs (risk of falling, walking speed and endurance, ability to get up and down), and the preferred educational graphic.
This study had two purposes. In the first phase, our purpose was to determine the feasibility and outcomes of the Mobility Checkup. In the second phase, our purpose was to identify preferences of older adults regarding this model of care using a DCE.

\section{METHODS \\ Description of the Mobility Checkup}

The Mobility Checkup was designed to establish baseline physical performance and identify preclinical and mobility disability in older adults. To ensure the broadest possible definition of impairment was captured, the following 4 categories of mobility were assessed using performance measures: transitions (ie, ability to transfer from sitting to standing and up from the floor), walking speed, walking endurance, and balance (Table 1). All measures used for the Mobility Checkup have been thoroughly described elsewhere ${ }^{22,36-56}$ and were selected based on psychometric properties, recommendations for use with older adults, and the availability of existing normative data. Ease of administration, time for administration, the ability to measure change across time, ${ }^{22}$ and predictability of future performance ${ }^{57}$ also were considered. The Timed Up From Floor (TUFF) test is the least established measure used in the Mobility Checkup and was chosen because it is known to be a physically challenging test ${ }^{23}$ that may identify functional limitations that other measures do not. ${ }^{24}$

Individualized education on physical performance formed the second part of the Mobility Checkup (Table 1 and Online Supplemental Figure S1). In a one-on-one discussion, each participant's physical performance measure values were compared to age-referenced norms for each mobility measure. Education on performance compared to age-referenced norms is motivating and provides tangible rationale for changes to activity or exercise programs. ${ }^{18}$

\section{Participants}

For the study's feasibility phase, potential participants were recruited through an assisted living facility and the academic institution in which the research was conducted. They met the criteria of being $\geq 55$ years of age, able to walk independently with or without an assistive device, able to follow 3-step commands, and able to understand the study tasks and purpose. Potential participants were excluded if, based on self-report, they were experiencing an acute illness, had a traumatic injury such as a fracture that affected their mobility, or a cardiac procedure or myocardial infarction in the last 6 months.

In the DCE phase, to achieve a more heterogeneous sample, potential participants were recruited from libraries, 2 residential facilities, and the academic institution in which the research was conducted. 
Table 1. The Mobility Checkup

\begin{tabular}{|c|c|}
\hline Measurement & Task/Test Used to Obtain \\
\hline Biometrics & Resting heart rate, blood pressure, weight, height \\
\hline \multicolumn{2}{|l|}{ Mobility categories } \\
\hline Transitions & Five Times Sit to Stand ${ }^{36-40}$ and Timed Up From Floor ${ }^{41-45}$ tests \\
\hline Walking speed & 10-meter walk test (normal and fast) ${ }^{22,46-48}$ \\
\hline Endurance & 6-minute walk test ${ }^{22,49,50}$ \\
\hline Balance & Functional Gait Assessment ${ }^{51,52}$ and Activities-specific Balance Confidence scale ${ }^{53-56}$ \\
\hline Education & Description \\
\hline Value of physical performance & $\begin{array}{l}\text { Participants were educated about the value of physical performance measures as } \\
\text { indicators of health status. }\end{array}$ \\
\hline Comparison to norms & $\begin{array}{l}\text { Participant scores were compared to age-referenced norms using a graphic. See } \\
\text { Online Supplemental Figure S1 for example. It was discussed with participants how } \\
\text { past performance would also be referenced in future Mobility Checkups. Participants } \\
\text { were provided a pocket card that indicated their scores and the normative values for } \\
\text { their age. See Online Supplemental Figure S1 for example. }\end{array}$ \\
\hline Recommendations & $\begin{array}{l}\text { Participants were provided recommendations on how they could use activity to } \\
\text { maintain or improve their mobility. If there was a concern regarding safety during } \\
\text { mobility, participants were recommended to have a full physical therapy evaluation. }\end{array}$ \\
\hline
\end{tabular}

Criteria included being $\geq 55$ years of age, able to walk independently with or without an assistive device, and able to understand the study tasks and purpose.

Participants provided written informed consent prior to participating in either institutional review board-approved phase of this study (feasibility protocol: \#2018-12-050; DCE protocol: \#1532773-1).

\section{Mobility Checkup Feasibility Testing}

The study was conducted at 2 sites: the community room in the assisted living facility and the research laboratory of the academic physical therapy program. Participants completed a one-time visit in which demographic information was collected and the Mobility Checkup was conducted by student physical therapists who were trained in study procedures and directly supervised by a licensed physical therapist. For this study, the operational definition of preclinical mobility disability was a score below the 50th percentile of the age-referenced norm on any measure. Education was provided to each participant on how they compared to norms for each measure and how they could use activity to maintain or improve their physical performance. Because the TUFF lacks age-referenced norms for males, the female norms were applied for all participants. The Short Assessment for Patient Satisfaction (SAPS) ${ }^{58}$ was completed by each participant following the Mobility Checkup. Each of the 7 SAPS items was scored from 0 to 4 . A total score of 28 represents high satisfaction. Satisfaction was reported as a percentage of the total score. ${ }^{59}$

Six criteria and thresholds were established a priori to determine the feasibility of the Mobility Checkup. Criteria included identification of preclinical or mobility disability, participant cancellation rate, Mobility Checkup duration, participant satisfaction, participant rating of the usefulness of education, and adverse events occurring during the checkup. Adverse events were defined as an injury resulting in prolonged hospitalization, disability or death, caused by the checkup. ${ }^{60}$ The primary outcome measures were identification of preclinical mobility disability in $\geq 25 \%$ of the study sample and participation rate. The confidence interval approach was used to determine the sample size based on participation rate. With 30 participants, we could estimate a $50 \%$ participation rate within a $95 \% \mathrm{CI}$ of $\pm 9 \% .{ }^{61}$

\section{Development of Discrete Choice Experiment Attributes and Attribute Levels}

Four attributes of the Mobility Checkup were evaluated in the DCE: preferred out-of-pocket cost, visit duration, desired education on specific mobility constructs (risk of falling, walking speed and endurance, ability to get up and down), and the preferred educational graphic. Levels of each attribute in the DCE were guided by the literature. More specifically, the cost attribute was determined based on realistic out-of-pocket expenditure estimates. ${ }^{62-64}$ 
The visit duration attribute levels were determined based on physical therapy visits typically lasting 30 to 60 minutes. ${ }^{65}$ The levels of educational content (ability to get up and down, walking speed and endurance, and fall risk) were chosen to identify the participant's greatest area of concern within mobility. Because visual display of test outcomes can increase their meaningfulness, ${ }^{66}$ we evaluated two types of educational graphics. Each style of graphic was presented with equal representation of improved and declined hypothetical example outcomes. An example choice set from the DCE is shown in Online Supplemental Figure S2.

To allow the main effects of each attribute in the DCE model to be examined, a simple fractional factorial design was used. A total of 24 possible profile alternatives were examined across 2 surveys, thus, the participants each completed 1 survey with 12 choice sets. The relatively small number of choice sets per survey was chosen to reduce the likelihood of respondent fatigue. ${ }^{32}$ As 20 respondents per survey is recommended, ${ }^{33}$ our original sample size estimate was 40 participants. Relative independence of the attributes studied eliminated the problem of implausible attribute combinations. The design was considered to have "level balance" because the total number of alternatives, 24 , is divisible by our attributes with 2, 3, or 4 levels. ${ }^{32}$ A design efficiency of $97 \%$ was achieved. The choice design was generated in $\mathrm{JMP}^{\circledR}$ 13.2.0 software (SAS Institute Inc.).

\section{DCE Implementation}

In a single study visit, participants provided demographic information, height and weight, and completed the Montreal Cognitive Assessment (MoCA). Participants then completed questions regarding their participation in preventive health care. Because these participants were not familiar with the concept of a Mobility Checkup, they were introduced to its content and purpose by viewing a 2-minute educational video (available at https://www. youtube.com/watch?v=gq9AQ16BUKU). Finally, the following instructions for the DCE were read to the participant: "You'll be presented with 2 scenarios, options A and B. After you have read and considered them both, please select the scenario that is most desirable to you." Participants completed the DCE and were not allowed to opt-out for any choice set.

\section{Statistical Analysis}

For the feasibility phase, descriptive statistics were used to characterize participants and outcomes. DCE responses were analyzed using conjoint choice modeling to estimate the main effect for each attribute for the full sample of participants. ${ }^{32}$ Choice modeling uses conditional logistic regression to estimate the probability that a configuration is preferred based on responses to combinations of levels of attributes. Unlike simple logistic regression, choice modeling uses a linear model to model choices based on response attributes to estimate the value or "utility" each participant attaches to the different levels of the attributes studied. The false discovery rate (FDR) P-value for each model effect was calculated using the BenjaminiHochberg technique, ${ }^{67}$ with alpha set at $\mathrm{P}<0.05$. Utility is the numerical representation of the level of desirability participants expressed for each level of each attribute and overall. Utility is arbitrarily scaled and zero-centered, where higher levels represent more desirability and lower (or negative) values represent less desirability. Utility balance improves efficiency in choice designs. ${ }^{68}$

A likelihood ratio test based on chi-squared P-value was used to determine if the observed frequencies of each level differ from theoretically expected or chance frequencies. Statistical analyses were completed with JMP 13.2.0.

\section{RESULTS}

Participants were recruited and enrolled between January 2019 and March 2019 for the feasibility phase and between December 2019 and March 16, 2020, for the DCE, at which time data collection was discontinued secondary to the COVID-19 pandemic. Coincidentally, 31 participants completed each phase of the study. Participant demographics are shown in Table 2. Participant flow through each study phase is illustrated in Figure 1.

\section{Feasibility Phase Results}

Five of the 6 feasibility criteria for the Mobility Checkup were met (Table 3). Of 31 participants, 10 scored at or above the 50th percentile for their age on all measures. These participants were provided education about normal performance, and it was recommended they continue their exercise and activity routine. Conversely, 21 participants were identified as having preclinical or mobility disability because they scored below the 50th percentile for their age on 1 or more measures. These participants were provided education about normal performance and activities to improve performance. For 5 of the 21, a physical therapy evaluation was recommended because of concerns about their safety recognized during the Mobility Checkup.

The relationship among the mobility categories in which participants were below normal, summarized by a Venn diagram (Figure 2), had two notable features. When a participant was below the norm on one measure in a category, it was likely they were below the norm on a measure in another category, indicated by overlap in the diagram. The greatest number of participants (16 of 21) had an impaired ability to transition (based on their Five Times Sit to Stand Test performance, performance on TUFF, or both). 
Table 2. Study Participant Demographics

\begin{tabular}{|c|c|c|}
\hline Demographic & $\begin{array}{l}\text { Feasibility } \\
(n=31)\end{array}$ & $\begin{array}{c}\text { DCE } \\
(n=31)\end{array}$ \\
\hline Age in years, mean (SD) & $71.6(10.0)$ & $73.3(12.0)$ \\
\hline \multicolumn{3}{|l|}{ Sex } \\
\hline Female & $74 \%$ & $84 \%$ \\
\hline Body mass index, mean (SD) & $27.7(3.9)$ & $29.4(6.5)$ \\
\hline Race/Ethnicity & NA & \\
\hline White/Caucasian & & $100 \%$ \\
\hline Native American & & $6 \%$ \\
\hline Other & & $0 \%$ \\
\hline General health & NA & \\
\hline Excellent & & $13 \%$ \\
\hline Very good & & $42 \%$ \\
\hline Good & & $22.5 \%$ \\
\hline Fair & & $22.5 \%$ \\
\hline Cognitive test, mean (range) ${ }^{*}$ & $28(18-30)$ & $24(9-30)$ \\
\hline \multicolumn{3}{|l|}{ Education } \\
\hline Less than high school graduate & $0 \%$ & $10 \%$ \\
\hline High school graduate & $6 \%$ & $25 \%$ \\
\hline 2-year degree or some college & $13 \%$ & $23 \%$ \\
\hline 4-year college graduate & $68 \%$ & $19 \%$ \\
\hline More than a 4-year degree & $13 \%$ & $23 \%$ \\
\hline \multicolumn{3}{|l|}{ Residence type } \\
\hline House & $71 \%$ & $35.5 \%$ \\
\hline Apartment & $16 \%$ & $35.5 \%$ \\
\hline Assisted living & $13 \%$ & $29 \%$ \\
\hline Household income & NA & \\
\hline$<\$ 30,000$ & & $29 \%$ \\
\hline$>\$ 30,000$ & & $52 \%$ \\
\hline Preferred not to answer & & $19 \%$ \\
\hline Employment & NA & \\
\hline Full-time & & $32 \%$ \\
\hline Part-time & & $7 \%$ \\
\hline Retired & & $58 \%$ \\
\hline Other & & $3 \%$ \\
\hline \multicolumn{3}{|l|}{ Assistive device used most often } \\
\hline None & $77 \%$ & $61 \%$ \\
\hline Cane or walking stick & $10 \%$ & $13 \%$ \\
\hline Walker (any type) & $13 \%$ & $26 \%$ \\
\hline \multicolumn{3}{|l|}{ Insurance } \\
\hline Medicare and/or Medicaid & NA & $16 \%$ \\
\hline Medicare + supplemental & & $42 \%$ \\
\hline Private insurance & & $39 \%$ \\
\hline Other & & $3 \%$ \\
\hline
\end{tabular}

${ }^{*}$ Cognitive tests implemented were Mini Mental Status Examination (verbally administered) for the feasibility phase and Montreal Cognitive Assessment for the DCE phase.

DCE, discrete choice experiment; NA, not assessed; SD, standard deviation.

\section{DCE Results}

Overall, 94\% of study participants reported using preventive health care and $97 \%$ indicated that they would participate in a Mobility Checkup if one were available to them. Participant opinions varied on how frequently they would prefer to have a Mobility Checkup: 26\% indicated they would prefer it occur biannually, 52\% preferred annually, and $22 \%$ thought every 2 years would be best. The majority (68\%) indicated they would prefer their results communicated on a paper handout, while the remaining $32 \%$ preferred an electronic communication.

All 31 participants who enrolled in the study completed the DCE survey; mean time to complete was 40 minutes. A total of 372 observations ( 31 participants $\times 12$ choice sets) were included in the DCE analysis. All attributes were statistically significant in their contribution to the model. Mean utility levels, 95\% CIs, P-values, and attribute importance are shown in Table 4. Participants' strong preference was to have no out-of-pocket cost for the Mobility Checkup, as compared to $\$ 25$ or $\$ 129$ co-pays. For each other attribute, the preferred choice was chosen statistically more frequently than chance, however, the difference between levels of the attributes was less than for cost and they were less important to the model.

\section{DISCUSSION}

This 2-phase study illustrates the feasibility of and older adults' preferences for the Mobility Checkup, a novel preventive model of physical therapy care. The Mobility Checkup builds on the American Physical Therapy Association suggestion of an annual physical therapy evaluation; however, it is more specific in that it is a standardized assessment of mobility of older adults. Herein, how the findings from both study phases might inform the ongoing development of the Mobility Checkup will be discussed.

The Mobility Checkup was found feasible, safe to administer, and of high interest to study participants, who reported high satisfaction and rated the education they received as very useful. The identification of $68 \%$ of participants as having preclinical mobility disability exceeded our established feasibility threshold of $25 \%$. One factor likely impacting this finding was that this study operationalized the 50th percentile of the agereferenced norms for each measure as a cutoff for preclinical mobility disability. Measures of the ability to transition identified the greatest number of participants below the 50th percentile for their age, suggesting this is an important category to include in the Mobility Checkup. To contribute best to the Mobility Checkup, scoring for the TUFF ${ }^{43}$ should be expanded to include those who require assistance and normative data for males should be 


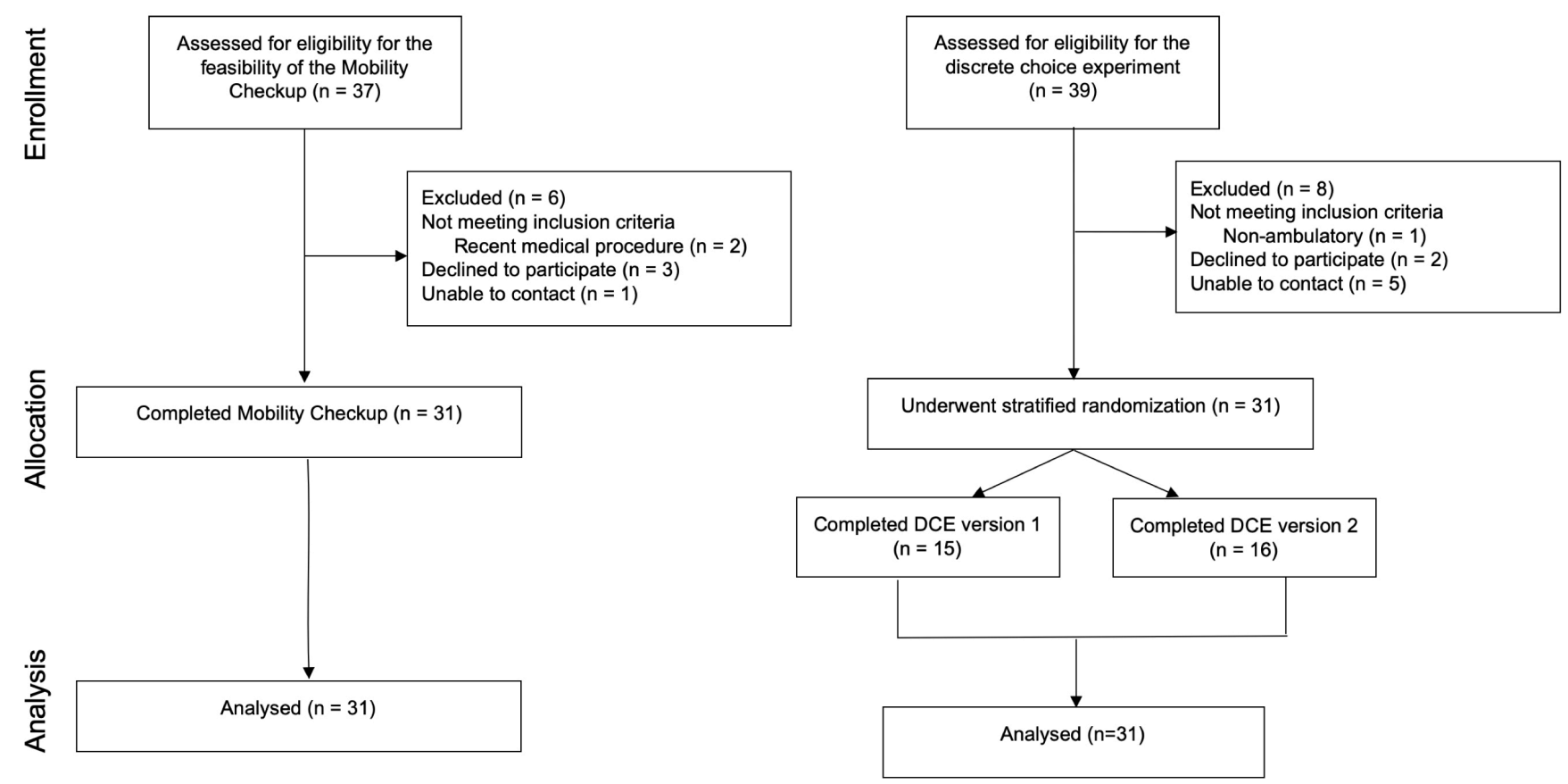

Figure 1. The enrollment, allocation of participants, and number of participants analyzed is shown in CONSORT diagrams for the Mobility Checkup and discrete choice experiment study phases.

Table 3. Mobility Checkup Feasibility Outcomes

\begin{tabular}{|c|c|c|c|}
\hline Criteria & $\begin{array}{l}\text { Threshold for } \\
\text { feasibility }\end{array}$ & Outcome & $\begin{array}{l}\text { Threshold } \\
\text { met/not met }\end{array}$ \\
\hline Identification of preclinical mobility disability & $\geq 25 \%$ & $68 \%$ & Met \\
\hline No show/cancellation rate & $\leq 10 \%$ & $9.1 \%$ & Met \\
\hline Checkup duration & $100 \%$ at $\leq 60$ minutes & $\begin{array}{l}18 \text { visits of } \leq 60 \\
13 \text { visits of }>60\end{array}$ & Not met \\
\hline Satisfaction per SAPS, ${ }^{45}$ mean (range) & $\geq 90 \%$ very satisfied & $91 \%(71-100)$ & Met \\
\hline Usefulness of the education, ${ }^{*}$ mean (range) & $\geq 80 \%$ satisfied & $98 \%(80-100)$ & Met \\
\hline Adverse events & None & None & Met \\
\hline
\end{tabular}

*Item 2 on SAPS.

SAPS, Short Assessment of Patient Satisfaction.

developed. Future studies should use cutoffs established by each individual measure. Regardless of cutoff, the data suggest measures used in the Mobility Checkup will identify individuals who would benefit from preventive care to maintain or improve mobility.

Nearly $42 \%$ of the Mobility Checkups conducted took longer than 60 minutes. There was overlap in the identification of preclinical mobility disability between measures and categories (Figure 2). The results of the DCE indicated participants prefer a shorter visit duration. Taken together, these data suggest it may be possible to reduce the number of tests and therefore the duration of the Mobility Checkup while retaining the ability to identify mobility disability in this population. Modifications to reduce Mobility Checkup duration may include eliminating the 10-meter walk test's fast speed, the Activities-specific Balance Confidence (ABC) scale, and/ or the Functional Gait Assessment (FGA). Disadvantages of the $\mathrm{ABC}$ include subjectivity, lack of identification of the type of balance problem, and lack of correlation to falls. ${ }^{69}$ The 10 -meter walk test's self-selected speed is the 


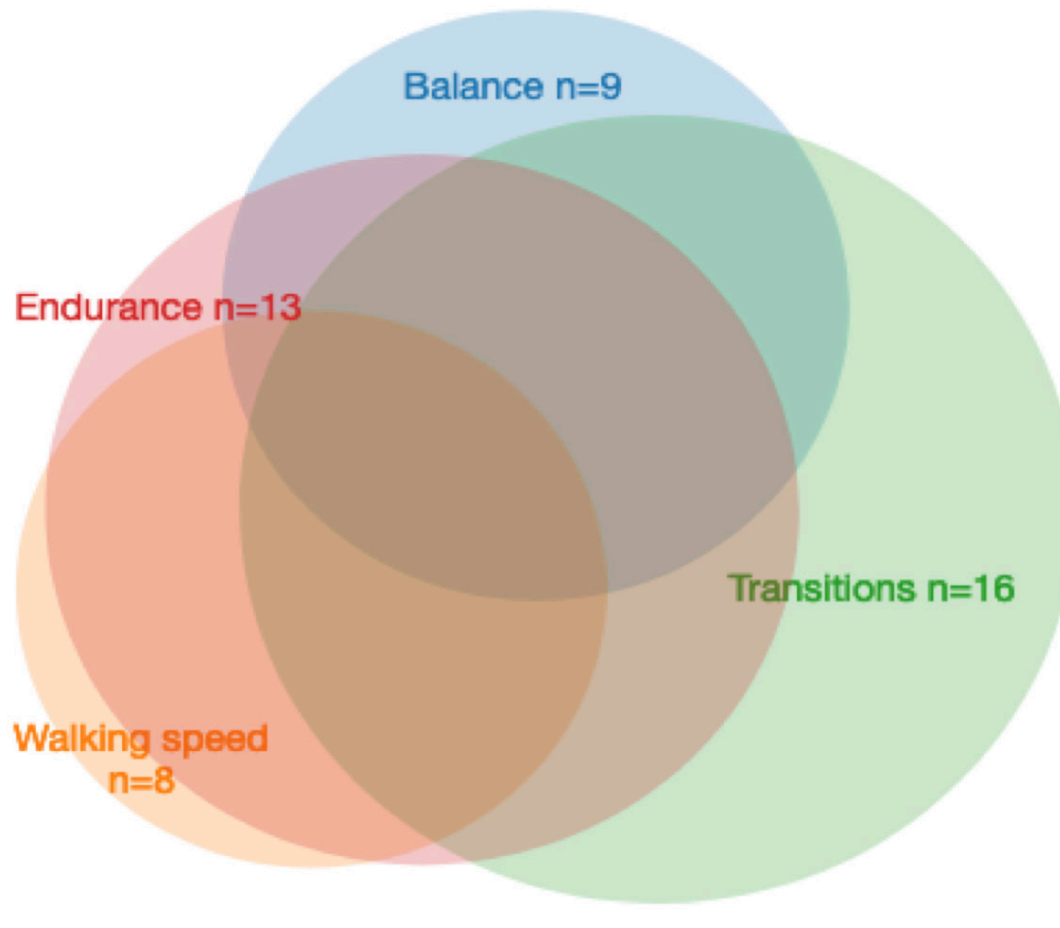

Figure 2. The Venn diagram includes data from 21 study participants who were below the 50th percentile on the age-referenced normative value for at least 1 measure (no overlap) or more than 1 (overlap) mobility category. Most participants were below average in $>1$ category. most well-established predictor of future performance, which suggests its fast speed measure could be eliminated. Replacing the FGA with a brief but challenging balance measure warrants consideration because several of the measures used correlate with fall risk and the FGA takes relatively longer to administer. Gait speed, as assessed with the 10-meter walk test and the 6-minute walk test, are recognized by non-physical therapy health care professions as useful for assessing functional capacity and as prognostic tools, which supports keeping these physical performance measures as part of the Mobility Checkup. ${ }^{48,70,71}$

DCEs are novel and patient-centered. A strength of the design is the ability to determine preferences in a way that reduces the likelihood of bias or misunderstandings due to subjectivity inherent in traditional surveys. The overwhelming preference of participants in this DCE was for no out-of-pocket cost for the Mobility Checkup. The cost of a service is known to be important to health care consumers. ${ }^{72}$ When evaluating participant preference in health care DCEs, others have found the cost attribute makes the design unbalanced. ${ }^{73}$ Future DCEs should focus on other important questions related to the cost of the service to the consumer in order to balance the design and yield more information from the other attributes in the model. For example, it should be possible to determine how participants value knowing what a service costs prior to receiving the service, knowing what proportion of the cost insurance covers, or knowing how to minimize their overall health care expenditures. ${ }^{72}$

For adults over 65 years old, a Mobility Checkup could be reimbursed as part of annual wellness visits ${ }^{74}$ which have been reimbursed through Medicare since 2011. They include measures of mobility and fall risk; however, physical therapists have not established a standard role in the annual wellness visit. As experts in the movement system, ${ }^{75}$ physical therapists are uniquely prepared to diagnose preclinical mobility disability and mobility disability ${ }^{76}$ and to guide the use of physical activity to optimize mobility as they age. ${ }^{18}$ Thus, physical therapists are the logical provider for this assessment.

In order for data collected during the Mobility Checkup to be useful in educating participants, it must be presented in an understandable way. One goal of the checkup's design was to educate participants about their scores in relation to agereferenced norms. Learning the "average" performance has been shown to be a valuable reference point in educational graphics. ${ }^{77}$ Another goal was to compare participants' scores to their past performance, when available. Future studies should add a measure of the likelihood of change in behavior based on the education provided.

Graphics are useful tools to convey the meaning of outcomes for patient education. ${ }^{66}$ Two graphic styles 
Table 4. Discrete Choice Experiment Results

\begin{tabular}{|c|c|c|c|c|c|c|}
\hline Attribute & Level & Utility & $95 \% \mathrm{Cl}$ & FDR $P$ & $\mathrm{X}^{2} P$ & $\begin{array}{c}\text { Attribute } \\
\text { importance }^{a}\end{array}$ \\
\hline Visit duration & $\begin{array}{l}30 \text { minutes } \\
60 \text { minutes }\end{array}$ & $\begin{array}{r}0.168 \\
-0.168\end{array}$ & $\begin{array}{c}0.022,0.318 \\
\text { NA }\end{array}$ & 0.022 & 0.022 & 0.032 \\
\hline Outcomes & $\begin{array}{l}\text { Ability to get up and down } \\
\text { Risk of falling } \\
\text { Walking speed and endurance }\end{array}$ & $\begin{array}{l}-0.095 \\
0.293 \\
-0.198\end{array}$ & $\begin{array}{c}-0.344,0.148 \\
0.079,0.517 \\
\text { NA }\end{array}$ & 0.022 & 0.019 & 0.047 \\
\hline Out-of-pocket cost & $\begin{array}{l}\$ 0 \text { cost } \\
\$ 25 \text { cost } \\
\$ 129 \text { cost }\end{array}$ & $\begin{array}{r}1.205 \\
0.163 \\
-1.369\end{array}$ & $\begin{array}{c}0.972,1.462 \\
-0.041,0.372 \\
\text { NA }\end{array}$ & $<0.001$ & $<0.001$ & 0.872 \\
\hline Educational graphic & $\begin{array}{l}\text { Bar-negative } \\
\text { Bar-positive } \\
\text { Graph-negative } \\
\text { Graph-positive }\end{array}$ & $\begin{array}{l}0.239 \\
0.320 \\
-0.122 \\
-0.438\end{array}$ & $\begin{array}{c}-0.079,0.564 \\
0.033,0.619 \\
-0.394,0.148 \\
\text { NA }\end{array}$ & 0.015 & 0.007 & 0.093 \\
\hline
\end{tabular}

FDR, false discovery rate; NA, not available; $X^{2}$, chi-squared test.

${ }^{a}$ The relative importance of each attribute to the model when the stated attributes are present. The importance scores sum to 1.0 and can be interpreted as proportions.

were evaluated in the DCE. Regardless of whether the graphic portrayed their results as better than or worse than their hypothetical past performance, participants preferred a colored bar graph (Table 4). This result is similar to another study that found patients prefer simple line graphs for ease of understanding patient-reported outcomes. ${ }^{78}$ Future studies of the Mobility Checkup will develop and evaluate the effectiveness of specific activity recommendations to reduce mobility disability.

Of the choices provided, participants indicated that education about their risk of falling was relatively more important than the other mobility categories, indicated by a utility of 0.293 and $95 \%$ CI of $0.079-0.517$ (Table 4). It is possible this was their preference because falls are a well-known risk of aging. This result suggests older adults would benefit from education on the predictive value of other aspects of their physical performance and their relationship with morbidity, mortality, future health status, and ability to live independently. ${ }^{48}$

\section{Strengths, Limitations, and Future Research}

Both phases of this study inform future research and development of the Mobility Checkup as a preventive model of physical therapy care. The participant sample in the feasibility phase was homogeneous; in particular, participants were well educated $(68 \%$ with a bachelor's degree) compared to the general population (in which about one-third of people achieve this degree). ${ }^{79}$ Recruitment of participants from a broader number and type of settings within the community for the DCE phase resulted in a sample with more balanced distribution across education level, type of residence, and assistive device (Table 2); however, in both study phases, female participants were more represented than males. Future studies may consider blocked enrollment to ensure the sample demographics reflect the population.

It is recommended DCEs be conducted face-to-face; ${ }^{33}$ however, it is possible this practice introduces bias. Our DCE was conducted face-to-face to allow participants to ask questions. A strength of this approach is it results in a high completion rate and allows study personnel to observe and answer questions as they arise. Study personnel's impression was that participants understood the attributes and levels based on the spontaneity of responses and the relative infrequency of questions. Participant understanding should be systematically assessed $^{33}$ in future studies in which participants complete the surveys independently after instruction. A strength of this study is that the threat of multiplicity is negligible. The feasibility criteria were largely independent, and conjoint analysis, used for the DCE, corrects statistically for the multiple tests using false discovery rate.

The proportion of eligible people who were willing to participate in the feasibility study was approximately $80 \%$. This information will be useful in calculating a sample size for future studies. The scientific objective of a future study could be to determine whether or not the Mobility Checkup identifies preclinical or mobility disability in a representative sample of older adults. Subsequently, the likelihood participants will change their behavior and effectiveness of the Mobility Checkup could be examined. 


\section{CONCLUSIONS}

This newly designed Mobility Checkup was feasible and well-received. Knowing what their physical performance measures might predict about their health, as well as knowing the cost of health care, was important to the older adults taking part in this study. Participants preferred a shorter visit duration, which would reduce the number of measures evaluated by the Mobility Checkup. However, the ability to transition - such as from sitting to standing or getting up from the floor should continue to be included.

\section{Patient-Friendly Recap}

- Gradual decline in mobility may go unnoticed by patients and clinicians alike. Physical therapists can safely administer tests to measure performance in walking speed, rising, balancing, etc.

- Authors compiled several preestablished mobility measures to develop a Mobility Checkup for older adults (age $\geq 55$ ).

- The checkup was found to be feasible to conduct in a community setting, though it frequently exceeded the goal length of 60 minutes. Still, most participants expressed high satisfaction with the education they received.

- The Mobility Checkup's most impactful evaluation was on one's ability to transition from one position (eg, sitting) to another (eg, standing).

\section{Author Contributions}

Study design: Lieberz, Borstad. Data acquisition or analysis: all authors. Manuscript drafting: Lieberz, Borstad. Critical revision: all authors.

\section{Conflicts of Interest}

None.

\section{References}

1. Musich S, Wang SS, Ruiz J, Hawkins K, Wicker E. The impact of mobility limitations on health outcomes among older adults. Geriatr Nurs. 2018;39:162-9. Crossref

2. Fried LP, Herdman SJ, Kuhn KE, Rubin G, Turano K. Preclinical disability: hypotheses about the bottom of the iceberg. J Aging Health. 1991;3:285-300.

3. Cavanaugh EJ, Richardson J, McCallum CA, Wilhelm M. The predictive validity of physical performance measures in determining markers of preclinical disability in communitydwelling middle-aged and older adults: a systematic review. Phys Ther. 2018;98:1010-21. CrossRef

4. World Health Organization. Healthy ageing and functional ability. Posted October 26, 2020; accessed January 11, 2021. https://www.who.int/news-room/questions-and-answers/item/ healthy-ageing-and-functional-ability
5. Fried LP, Bandeen-Roche K, Chaves PH, Johnson BA. Preclinical mobility disability predicts incident mobility disability in older women. J Gerontol A Biol Sci Med Sci. 2000;55(1):M43-52. Crossref

6. Beauchamp MK. Screening for preclinical balance limitations in younger older adults: time for a paradigm shift? Phys Ther. 2020;100:589-90. Crossref

7. Gill TM, Allore HG, Hardy SE, Guo Z. The dynamic nature of mobility disability in older persons. J Am Geriatr Soc. 2006;54:248-54. CrossRef

8. Buttorf C, Ruder T, Bauman M. Multiple Chronic Conditions in the United States. RAND Corporation; 2017. https://www. rand.org/content/dam/rand/pubs/tools/TL200/TL221/RAND TL221.pdf

9. Domenichiello AF, Ramsden CE. The silent epidemic of chronic pain in older adults. Prog Neuropsychopharmacol Biol Psychiatry. 2019;93:284-90. Crossref

10. Nguyen QD, Wu C, Odden MC, Kim DH. Multimorbidity patterns, frailty, and survival in community-dwelling older adults. J Gerontol A Biol Sci Med Sci. 2019;74:1265-70. Crossref

11. HealthinAging.org. Caregiver guide: mobility problems. Acccessed June 8, 2021. https://www.healthinaging.org/toolsand-tips/caregiver-guide-mobility-problems

12. Iezzoni LI, McCarthy EP, Davis RB, Siebens H. Mobility impairments and use of screening and preventive services. $\mathrm{Am}$ J Public Health. 2000;90:955-61. CrossRef

13. Groessl EJ, Kaplan RM, Rejeski WJ, et al. Physical activity and performance impact long-term quality of life in older adults at risk for major mobility disability. Am J Prev Med. 2019;56:141-6. Crossref

14. Rosenwohl-MackA, Schumacher K, Fang ML, Fukuoka Y. Anew conceptual model of experiences of aging in place in the United States: results of a systematic review and meta-ethnography of qualitative studies. Int J Nurs Stud. 2020;103:103496. Crossref

15. Auais M, Ahmed T, Alvarado B, et al. Gender differences in four-year incidence of self-reported and performance-based functional disability: the International Mobility in Aging study. Arch Gerontol Geriatr. 2019;82:266-72. Crossref

16. American Physical Therapy Association. Annual physical therapy visit. Accessed January 12, 2021. https://www.apta. org/patient-care/interventions/annual-checkup

17. Lowe A, Gee M, McLean S, Littlewood C, Lindsay C, Everett S. Physical activity promotion in physiotherapy practice: a systematic scoping review of a decade of literature. Br J Sports Med. 2018;52:122-7. CrossRef

18. Avers D. The value of geriatric physical therapy: excerpts from 'We Can Do Better': 2020 Carole B. Lewis Distinguished Lecture: address to the APTA Geriatrics Membership at the Combined Sections Meeting, Denver, CO, February 13, 2020. J Geriatr Phys Ther. 2020;43:115-9. CrossRef

19. Puthoff M. Participants' perceptions and the implementation of a physical fitness screen for aging adults. $J$ Geriatr Phys Ther. 2021;44(1):E1-8. CrossRef

20. Quinn L, Morgan D. From disease to health: physical therapy health promotion practices for secondary prevention in adult and pediatric neurologic populations. J Neurol Phys Ther. 2017;41 Suppl 3:S46-54. Crossref

21. Hambrook R, Middleton G, Bishop D, Crust L, Broom D. Time to speed up, not slow down: a narrative review on the importance of community-based physical activity among older people. J Health Soc Sci. 2020;5:91-102. 
22. Perera S, Mody SH, Woodman RC, Studenski SA. Meaningful change and responsiveness in common physical performance measures in older adults. $J$ Am Geriatr Soc. 2006;54:743-9. CrossRef

23. Ardali G, States RA, Brody LT, Godwin EM. Characteristics of older adults who are unable to perform a floor transfer: considerations for clinical decision-making. $J$ Geriatr Phys Ther. 2020;43:62-70. CrossRef

24. Cattuzzo MT, de Santana FS, Safons MP, et al. Assessment in the supine-to-stand task and functional health from youth to old age: a systematic review. Int J Environ Res Public Health. 2020;17(16):5794. CrossRef

25. Bubela D, Sacharko L, Chan J, Brady M. Balance and functional outcomes for older community-dwelling adults who practice tai chi and those who do not: a comparative study. J Geriatr Phys Ther. 2019;42:209-15. CrossRef

26. Covill LG, Utley C, Hochstein C. Comparison of ai chi and impairment-based aquatic therapy for older adults with balance problems: a clinical study. J Geriatr Phys Ther. 2017;40:204-13. CrossRef

27. Son NK, Ryu YU, Jeong HW, Jang YH, Kim HD. Comparison of 2 different exercise approaches: tai chi versus Otago, in community-dwelling older women. J Geriatr Phys Ther. 2016;39:51-7. CrossRef

28. Pietrzak E, Cotea C, Pullman S. Using commercial video games for falls prevention in older adults: the way for the future? J Geriatr Phys Ther. 2014;37:166-77. CrossRef

29. Wurzer B, Waters DL, Hale LA. Fall-related injuries in a cohort of community-dwelling older adults attending peer-led fall prevention exercise classes. J Geriatr Phys Ther. 2016;39:110-6. CrossRef

30. Dipietro L, Campbell WW, Buchner DM, et al. Physical activity, injurious falls, and physical function in aging: an umbrella review. Med Sci Sports Exerc. 2019;51:1303-13. CrossRef

31. Sweeting KR, Whitty JA, Scuffham PA, Yelland MJ. Patient preferences for treatment of achilles tendon pain: results from a discrete-choice experiment. Patient. 2011;4:45-54. CrossRef

32. Johnson FR, Lancsar E, Marshall D, et al. Constructing experimental designs for discrete-choice experiments: report of the ISPOR Conjoint Analysis Experimental Design Good Research Practices Task Force. Value Health. 2013;16:3-13. CrossRef

33. Lancsar E, Louviere J. Conducting discrete choice experiments to inform healthcare decision making: a user's guide. Pharmacoeconomics. 2008;26:661-77. CrossRef

34. Ryan M, Bate A, Eastmond CJ, Ludbrook A. Use of discrete choice experiments to elicit preferences. Qual Health Care. 2001;10 Suppl 1:i55-60.

35. Skjoldborg US, Lauridsen J, Junker P. Reliability of the discrete choice experiment at the input and output level in patients with rheumatoid arthritis. Value Health. 2009;12:153-8. CrossRef

36. Bohannon RW. Reference values for the five-repetition sitto-stand test: a descriptive meta-analysis of data from elders. Percept Mot Skills. 2006;103:215-22. CrossRef

37. Bohannon RW, Shove ME, Barreca SR, Masters LM, Sigouin C. Five-repetition sit-to-stand test performance by communitydwelling adults: a preliminary investigation of times, determinants, and relationship with self-reported physical performance. Isokinet Exerc Sci. 2007;15:77-81. CrossRef

38. Buatois S, Miljkovic D, Manckoundia P, et al. Five times sit to stand test is a predictor of recurrent falls in healthy community-living subjects aged 65 and older. J Am Geriatr Soc. 2008;56:1575-7. CrossRef
39. Mong Y, Teo TW, Ng SS. 5-repetition sit-to-stand test in subjects with chronic stroke: reliability and validity. Arch Phys Med Rehabil. 2010;91:407-13. CrossRef

40. Tiedemann A, Shimada H, Sherrington C, Murray S, Lord $\mathrm{S}$. The comparative ability of eight functional mobility tests for predicting falls in community-dwelling older people. Age Ageing. 2008;37:430-5. CrossRef

41. Naugle KM, Higgins TJ, Manini TM. Obesity and use of compensatory strategies to perform common daily activities in pre-clinically disabled older adults. Arch Gerontol Geriatr. 2012;54:e134-8. CrossRef

42. Moffett MA, Avers D, Bohannon RW, Shaw KL, Merlo AR. Performance and clinimetric properties of the timed up from floor test completed by apparently healthy communitydwelling older women. J Geriatr Phys Ther. 2021;44:159-64. CrossRef

43. Manckoundia P, Buatois S, Gueguen R, et al. Clinical determinants of failure in balance tests in elderly subjects. Arch Gerontol Geriatr. 2008;47:217-28. CrossRef

44. Bergland A, Wyller TB. Risk factors for serious fall related injury in elderly women living at home. Inj Prev. 2004;10:308-13. CrossRef

45. Bergland A, Laake K. Concurrent and predictive validity of "getting up from lying on the floor." Aging Clin Exp Res. 2005;17:181-5. CrossRef

46. Bohannon RW, Andrews AW, Thomas MW. Walking speed: reference values and correlates for older adults. J Orthop Sports Phys Ther. 1996;24:86-90. CrossRef

47. Fritz S, Lusardi M. White paper: "walking speed: the sixth vital sign." J Geriatr Phys Ther. 2009;32:46-9.

48. Peters DM, Fritz SL, Krotish DE. Assessing the reliability and validity of a shorter walk test compared with the 10-Meter Walk Test for measurements of gait speed in healthy, older adults. J Geriatr Phys Ther. 2013;36:24-30. CrossRef

49. Steffen TM, Hacker TA, Mollinger L. Age-and genderrelated test performance in community-dwelling elderly people: Six-Minute Walk Test, Berg Balance Scale, Timed Up \& Go Test, and gait speeds. Phys Ther. 2002;82:128-37. CrossRef

50. van Heuvelen MJ, Kempen GI, Brouwer WH, de Greef MH. Physical fitness related to disability in older persons. Gerontology. 2000;46:333-41. CrossRef

51. Wrisley DM, Kumar NA. Functional Gait Assessment: concurrent, discriminative, and predictive validity in community-dwelling older adults. Phys Ther. 2010;90:761-73. CrossRef

52. Walker WC, Pickett TC. Motor impairment after severe traumatic brain injury: a longitudinal multicenter study. J Rehabil Res Dev. 2007;44:975-82. CrossRef

53. Powell LE, Myers AM. The Activities-specific Balance Confidence (ABC) scale. J Gerontol A Biol Sci Med Sci. 1995;50A(1):M28-34. CrossRef

54. Cleary K, Skornyakov E. Predicting falls in community dwelling older adults using the Activities-specific Balance Confidence scale. Arch Gerontol Geriatr. 2017;72:142-5. CrossRef

55. Huang TT, Wang WS. Comparison of three established measures of fear of falling in community-dwelling older adults: psychometric testing. Int J Nurs Stud. 2009;46:1313-9. CrossRef

56. Nemmers TM, Miller JW. Factors influencing balance in healthy community-dwelling women age 60 and older. J Geriatr Phys Ther. 2008;31:93-100. CrossRef 
57. Wennie Huang WN, Perera S, VanSwearingen J, Studenski S. Performance measures predict onset of activity of daily living difficulty in community-dwelling older adults. $\mathrm{J} \mathrm{Am}$ Geriatr Soc. 2010;58:844-52. $\underline{\text { CrossRef }}$

58. Hawthorne G, Sansoni J, Hayes L, Marosszeky N, Sansoni E. Measuring patient satisfaction with health care treatment using the Short Assessment of Patient Satisfaction measure delivered superior and robust satisfaction estimates. J Clin Epidemiol. 2014;67:527-37. CrossRef

59. Pazit L, Jeremy D, Nancy B, Michael B, George E, Hill KD. Safety and feasibility of high speed resistance training with and without balance exercises for knee osteoarthritis: a pilot randomised controlled trial. Phys Ther Sport. 2018;34:154-63. CrossRef

60. Rafter N, Hickey A, Condell S, et al. Adverse events in healthcare: learning from mistakes. QJM. 2015;108:273-7. CrossRef

61. Hooper R. Justifying sample size for a feasibility study. Published 2014; accessed December 7, 2021. https://www.rds-london.nihr. ac.uk/wpcms/wp-content/uploads/2019/02/Justifying-samplesize-for-feasibility-study-updated-22-Feb-2019.pdf

62. Centers for Medicare \& Medicaid Services. Medicare coverage of therapy services. Revised June 2020; accessed December 7, 2021. https://www.medicare.gov/Pubs/pdf/10988-MedicareLimits-Therapy-Services.pdf

63. Centers for Medicare \& Medicaid Services. 2019 Medicare Parts A \& B premiums and deductibles. Published October 12, 2018; accessed December 1, 2020. https://www.cms.gov/newsroom/ fact-sheets/2019-medicare-parts-b-premiums-and-deductibles

64. MN Community Measurement. Health Care Cost \& Utilization in 2019 report released. Published November 10, 2020; accessed December 7, 2021. https://mncm.org/health-carecost-and-utilization-in-2019-report-released/

65. Edgar CB. Bechmarking PT programs. AAOS Now. Published October 1, 2014; accessed December 1, 2020. https://www. aaos.org/aaosnow/2014/oct/managing/managing6/

66. Zikmund-Fisher BJ, Scherer AM, Witteman HO, et al. Graphics help patients distinguish between urgent and nonurgent deviations in laboratory test results. $J$ Am Med Inform Assoc. 2017;24:520-8. CrossRef

67. Thissen D, Steinberg L, Kuang D. Quick and easy implementation of the Benjamini-Hochberg procedure for controlling the false positive rate in multiple comparisons. J Educ Behav Stat. 2002;27:77-83. CrossRef
68. Huber J, Zwerina K. The importance of utility balance in efficient choice designs. J Mark Res. 1996;33:307-17. CrossRef

69. Mancini M, Horak FB. The relevance of clinical balance assessment tools to differentiate balance deficits. Eur J Phys Rehabil Med. 2010;46:239-48.

70. Du H, Newton PJ, Salamonson Y, Carrieri-Kohlman VL, Davidson PM. A review of the six-minute walk test: its implication as a self-administered assessment tool. Eur $J$ Cardiovasc Nurs. 2009;8:2-8. CrossRef

71. Patrizio E, Calvani R, Marzetti E, Cesari M. Physical functional assessment in older adults. J Frailty Aging. 2021;10:141-9. CrossRef

72. Hirpa M, Woreta T, Addis H, Kebede S. What matters to patients? A timely question for value-based care. PLoS One. 2020;15(7):e0227845. CrossRef

73. Sever I, Verbič M, Klarić Sever E. Cost attribute in health care DCEs: just adding another attribute or a trigger of change in the stated preferences? J Choice Model. 2019;32:100135. CrossRef

74. Medicare Learning Network, Centers for Medicare \& Medicaid Services. Medicare wellness visits. Updated February 2021; accessed April 2021. https://www.cms.gov/Outreach-andEducation/Medicare-Learning-Network-MLN/MLNProducts/ preventive-services/medicare-wellness-visits.html

75. Sahrmann SA. The human movement system: our professional identity. Phys Ther. 2014;94:1034-42. Crossref

76. Sahrmann S. Defining our diagnostic labels will help define our movement expertise and guide our next 100 years. Phys Ther. 2021;101(1):pzaa196. Crossref

77. Tolbert E, Brundage M, Bantug E, et al. Picture this: presenting longitudinal patient-reported outcome research study results to patients. Med Decis Making. 2018;38:994-1005. CrossRef

78. Brundage MD, Smith KC, Little EA, Bantug ET, Snyder CF; PRO Data Presentation Stakeholder Advisory Board. Communicating patient-reported outcome scores using graphic formats: results from a mixed-methods evaluation. Qual Life Res. 2015;24:2457-72. CrossRef

79. Stoops N. Educational attainment in the United States: 2003. Issued June 2004; accessed December 7, 2021. https://www. census.gov/prod/2004pubs/p20-550.pdf

(C) 2022 Advocate Aurora Health, Inc. 